\title{
Empowering the Educational Magnificence of Students' Life Skills through Library Web 2.0 Services
}

\author{
Mohd Ismail Abidin \\ Universiti Teknologi MARA, Malaysia \\ mohdismail@bdrmelaka.uitm.edu.my \\ Mohd Ab Malek bin Md Shah \\ Universiti Teknologi MARA, Malaysia \\ malek625@bdrmelaka.uitm.edu.my \\ Mahdad Tajbakhsh Jadidi \\ Department of Library and Information Science, Faculty of Computer and Information Technology \\ University Malaya \\ mahdad777@yahoo.com \\ Kiran Kaur \\ Department of Library and Information Science \\ Faculty of Computer and Information Technology \\ University Malaya \\ kiran@um.edu.my \\ Sabariah $\mathrm{Hj}$. Mahat \\ Universiti Teknologi MARA, Malaysia \\ sabariah@melaka.uitm.edu.my
}

\begin{abstract}
Cognitive skills, personal skills, and inter-personal skills are the tripartite components which are vital in to the teaching process and system. Indeed, in order to empower students' competencies, it is undeniably true that school libraries have played a crucial role in materializing such magnificent achievement. This is due to the fact that as more schools add project-based learning to the curriculum, students need library skills to conduct research which is essential to completing their projects. Most importantly, students must master library skills in order to navigate problems which they might encounter in a real-life setting. In fact, some students, especially those in higher levels, do not receive direct instruction in regards to library skills, but learn them through activities that support the content areas instead. Thus, the main focus of this study is to explore an overall landscape of using Web 2.0 library services, as well as the awareness among students regarding the services offered by the library in developing their skills theoretically based on a practical approach. This study incorporates user survey to obtain the overall data use of library Web 2.0 services in general (public and academic libraries). A total of 657 people participated in this research. It is hoped that this study will increase the awareness of using library Web 2.0 services offered by the school libraries among students which could eventually enrich their life skills in facing their academic world holistically.
\end{abstract}

Keywords: cognitive skills, personal skills, inter-personal skills, competencies, library skills, Web 2.0 


\section{Introduction}

Schools and universities are no longer the only academic sources of information and knowledge. Without a doubt, the traditional literacy has been gradually extended to a multimedia literacy pertaining to the students' abilities of cognitive skills, personal skills, as well as inter-personal skills with digitally encoded materials (Nikolov, 1997). In relation to this, Web 2.0 and social media technologies contribute to an ongoing shift in learning styles and knowledge creation; as well as changing learner's information needs and expectation. The convergence of diverse philosophical and pedagogical concepts such as creation of new cognitive authorities, knowledge construction through individual learning styles, autonomy of the learner in formal educational contexts or the increasing role of informal learning promote innovative pedagogical approaches and models of to enhance learning. Online applications are increasingly ubiquitous, social, and participatory (Jenkins, 2006; Valkenburg \& Peter, 2009). Similarly, the studies carried out by Riza Ayu and Abrizah (2011) and Aziz, Arif, Ramly, Abdullah, and Husaini (2011) found out that Facebook is the most popular social media used by the academic libraries in Malaysia. In fact, the rise of online communities such as Facebook facilitates a participatory culture where individuals must develop literacies such as networking, information appropriation, remix, judgment, and collective intelligence.

\section{Application of Web 2.0 in Teaching and Learning Process}

The Web 2.0 virtual learning environments provide opportunities for students, academicians, parents and stakeholders in creating conducive atmosphere for teaching and learning process holistically. The emergence of Web 2.0 revolution is widely recognized (O'Reilly, 2005). In relation to this, it is undeniably true that today's learner does not merely read or consume content instantly. This is due to the fact that most of the students (generation $Y$ and Z) access Web 2.0 applications widely (Socialbakers.com, 2013). To support this remark, the latest research done by Mohd Ismail and Kiran (2012) indicated that the main purpose of Web 2.0 application development is for promotional purposes which could eventually lead towards a formation of bilateral communication between users and libraries. In relation to this situation, some of the Web 2.0 applications and services are blogs, wikis, RSS feeds, tagging and social bookmarking, multimedia sharing, podcasts, social networking (Abram, 2005).

\section{Research Aims and Methodology}

The main purpose of this research is to investigate the use of Web 2.0 offered by Malaysian public and academic libraries among Malaysian society. It also indirectly raises awareness about this application among library users in Malaysia. In addition, this research also aims to identify the extent of the service acceptance among users, and also to see how this application helps users in the education and learning process. It is compatible with the latest Malaysian social lifestyle where government promotes virtual learning or blended learning. To explore the use of Web 2.0 among users aged between 12 to 21 years old, these users were surveyed. A questionnaire consisting of 15 open-ended questions was used for this study. A total of 657 library patrons from various walks of life participated in this study.

\section{Result and Discussion Respondents' Background}

The profile information which was gathered from the respondents consists of gender, place of residence, and age. From the surveys, the majority of respondents are women (62.6), while the urban population is the largest respondents for this study, with $54 \%$. In terms of age, the 15-17 years respondents were the highest representing $42.8 \%$, followed by the age range of $12-14$ years (28.8\%). Almost $17.5 \%$ of respondents aged 21 years and above (See Table 1). Respondents were also asked whether they surfed the Internet or not. The results indicate, about $96.2 \%$ of them used for or been surfing the Internet in their daily lives. Only $3 \%$ of respondents had never used the Internet. 
Table 1: Respondent Profile

\begin{tabular}{|c|c|c|c|c|c|c|c|c|c|}
\hline \multicolumn{10}{|c|}{ Respondent Profile } \\
\hline \multicolumn{2}{|c|}{ Gender } & \multicolumn{2}{|c|}{ Place } & \multicolumn{2}{|c|}{ Age } & \multicolumn{2}{|c|}{ Use of Internet } & \multicolumn{2}{|c|}{ Place of Surfing Internet } \\
\hline & Frequency & & Frequency & & Frequency & & Frequency & & Frequency \\
\hline Male & $239(36.4 \%)$ & Urban & $355(54 \%)$ & 12-14Years & $189(28.8 \%)$ & Yes, Always & $299(45.5 \%)$ & Home & $504(76.7 \%)$ \\
\hline Female & $411(62.6 \%)$ & Rural & $291(44.3 \%)$ & $15-17$ years & $281(42.8 \%)$ & Yes, Sometimes & $333(50.7 \%)$ & CyberCafe & $295(44.9 \%)$ \\
\hline 99 & $7(1 \%)$ & 99 & $11(1.6 \%)$ & $18-20$ & $68(10.4 \%)$ & No, Never & $19(2.9 \%)$ & School/University & $216(32.9 \%)$ \\
\hline \multirow[t]{4}{*}{ I otal } & 657 & & 657 & 21 Above & $115(17.5 \%)$ & 99 & $6(1 \%)$ & Library & $128(19.5 \%)$ \\
\hline & & & & 99 & $4(0.6 \%)$ & & & Restaurant & $139(21.2 \%)$ \\
\hline & & & & Total & 657 & Total & 657 & Etc. & $20(3.7 \%)$ \\
\hline & & & & & & & & Total & 657 \\
\hline
\end{tabular}

This study also found that most of the respondents were comfortable with surfing the Internet at their homes, namely by $76.7 \%$ (504 respondents). Respectively, surfing the Internet in Cyber-café (44.9\%) and School/University (32.9\%) were second and third. Through this data we can assume that Internet use is still popular among users in Malaysian Cyber-cafés. The library is not the most popular place for users to surf the Internet (19.5\% only). This shows that many respondents do not like or show less interest to surf the Internet in the library. However, a survey conducted by Mohd Ismail and Kiran (2013) found that restrictions or limitation in the usage of Web 2.0 applications among library users in Malaysian discouraged youth from using Web 2.0 applications in libraries.

\section{The use and awareness of Web 2.0 existence}

Respondents were asked to indicate their understanding regarding the term Web 2.0 and the extent of using such applications. Based on the figure below, the majority of respondents are aware or familiar with web 2.0 applications $(62.7 \%)$. The highest majority of respondents who used or were aware of the existence of these applications lived in an urban area (287 respondents). The number of Females using web 2.0 applications (277 respondents) was much higher than the number of Males. Respondents in the 15-17 year age group had the highest awareness about web 2.0 applications (186 respondents). (See Figure 1)



Figure 1: Web 2.0 Awareness

Subsequent questions were asked from the respondents pertaining to types of Web 2.0 applications generally used by them. Respondents were given the option to provide multiple answers. Interestingly, Facebook was rated as the most popular application among respondents (84\%). $77.5 \%$ of respondents were following YouTube. Instant Messaging was the third commonly used application by the respondents. However, the lowest application 
that respondents did not know and use was RSS with only $7.9 \%$. Figure 2 shows the use of Web 2.0 application within the 3 categories of respondents.

\begin{tabular}{|c|c|c|c|c|c|c|c|c|c|}
\hline \multirow{2}{*}{ Type of Web 2.0 that ever used } & \multirow{2}{*}{\multicolumn{2}{|c|}{ By Category }} & \multicolumn{7}{|c|}{ Web 2.0 Aplicaton } \\
\hline & & & IM & RSS & Blog & Wikis & Flicker & Youtube & Facebook \\
\hline \multirow{8}{*}{ FACEBOOK $(84.5 \%)$} & \multirow{2}{*}{ Gender } & Male & 95 & 20 & 71 & 28 & 34 & 175 & 193 \\
\hline & & \begin{tabular}{|l|} 
Female \\
\end{tabular} & 219 & 32 & 158 & 76 & 56 & 333 & 359 \\
\hline & \multirow{2}{*}{ Place } & Urban & 194 & 17 & 144 & 66 & 49 & 300 & 326 \\
\hline & & Rural & 119 & 35 & 84 & 38 & 41 & 205 & 222 \\
\hline & \multirow{4}{*}{ Age } & \begin{tabular}{|c|}
$12-$ \\
14Years
\end{tabular} & 80 & 6 & 46 & 10 & 16 & 143 & 149 \\
\hline & & $\begin{array}{l}15-17 \\
\text { years }\end{array}$ & 125 & 35 & 90 & 32 & 44 & 215 & 242 \\
\hline & & $18-20$ & 28 & 5 & 20 & 8 & 9 & 45 & 57 \\
\hline & & 21 Above & 83 & 6 & 7 & 54 & 21 & 106 & 107 \\
\hline
\end{tabular}

Figure 2: Type of Web 2.0 Usage

The use and awareness of libraries Web 2.0 services

Respondents were asked whether they knew about Web 2.0 services offered by the libraries (public or academic library). $49 \%$ of respondents knew or might have used this application but the majority of them only knew about the existence of this application (41\%). Only $8 \%$ of the respondents are not sure of the existence of this application. From the total of $49.6 \%$ (people aware of this application), only $9.9 \%$ of respondents were using library's Facebook services. The second most visited services were Wikis (6.5\%). Instant Messaging and blogs $(5.3 \%)$ were chosen by same number (See Figure 3 ). The data showed a very large gap between respondents who have used this application in general and respondents who have never used Web 2.0 applications services offered by the library.

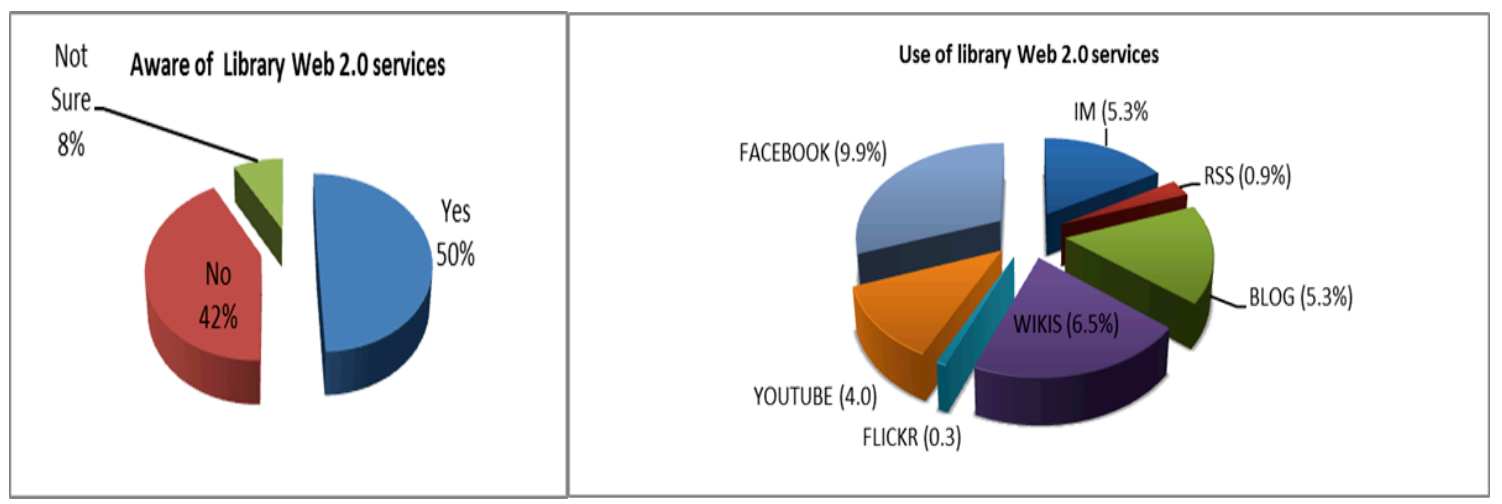

Figure 3: The Use and Awareness of Libraries Web 2.0 Services

Respondents were also asked about their knowledge of the existence and availability of library web 2.0 services (See Figure 4). The majority of respondents were aware of or knew about this service from libraries portal (34.1\%). Interestingly, the influence from friends also contributed to the relatively high percentage (33.6\%) in awareness among respondents of the existence of Web 2.0 services. We assumed that public/academic libraries actively promote these applications among their users through the figure below. The figure shows respondents were aware of these applications through the information that they saw in libraries banner/bunting (22.5\%), library orientation (20.7\%), libraries activities / program $(20.4 \%)$, Web 2.0 training/workshops (17.8\%), and library bulletin $(17.7 \%)$. Interestingly, $10.5 \%$ of the respondents were aware of the existence of these services through other sources such as family, teachers, lecturers, and so on. 


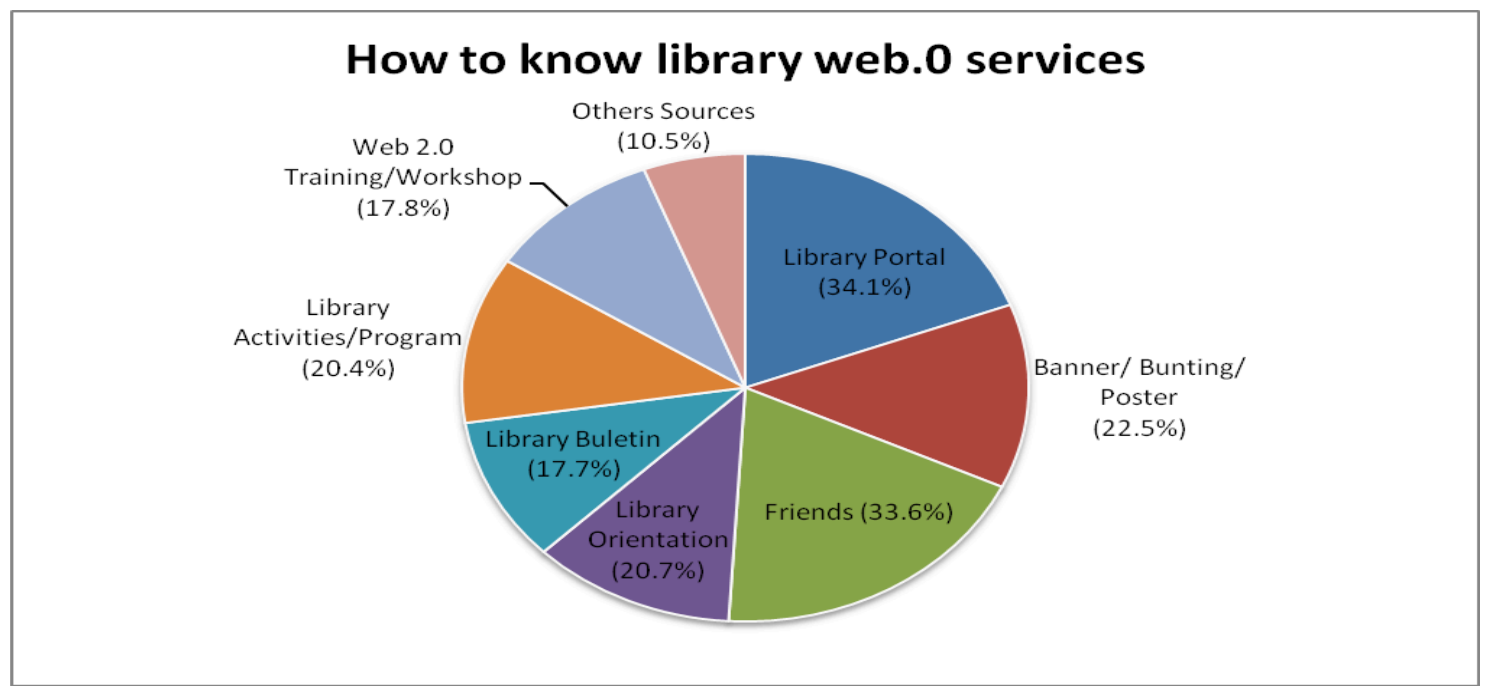

Figure 4: Medium Know Existence of Library Web 2.0 Services

To see the most common activities performed by respondents in the use of libraries Web 2.0 services, respondents were asked to assess 4 common things done while surfing this service. From the data below (see figure 5), it was found that the highest percentage of respondents evaluate the use of these four categories were in neutral (between always use it or not use it). The data also showed that the service most respondents used is to obtain library materials (30.7\% are frequently used), and also receive downloaded/uploaded documents, pictures, and library materials (13.9\% very frequently used). The first category using Web 2.0 services to obtain library information or general information, had the highest score: about $45.5 \%$ of respondents use was indicated as neutral, followed by the $15.2 \%$ of respondents who did not frequently use.

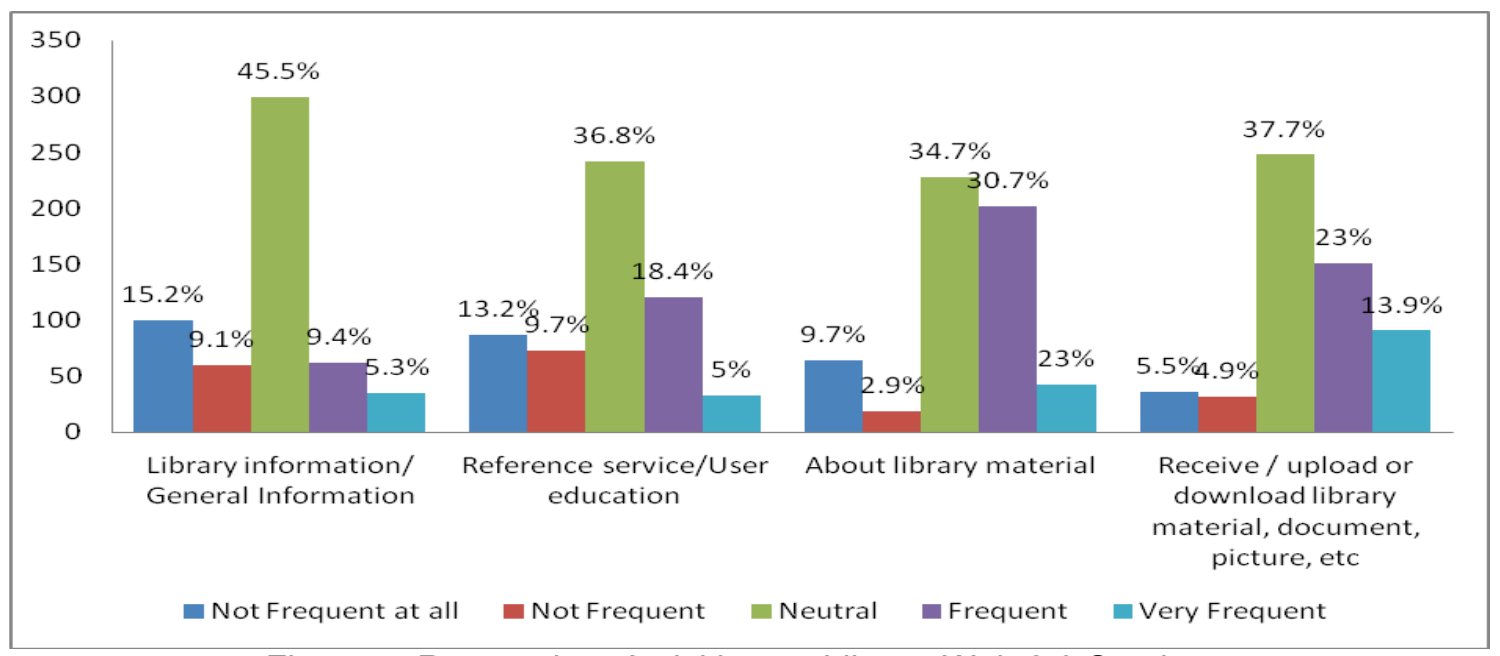

Figure 5: Respondent Activities on Library Web 2.0 Services

Respondents were also asked to indicate their experience using libraries web 2.0 services into 4 categories - (1) easy to use, (2) response time, (3) current or latest information and (4) quality of information. From the figure below (figure 6), the results indicated that the highest number of the respondents perceived that the application was at the level of "Good" and "Satisfactory". The highest score is by $40 \%$ of respondents which rated "Satisfactory" for the library response time and "Good" for the quality of information $(41.6 \%)$ provided in library web 2.0 services. The second highest score was $30 \%$ which rated "Satisfactory". More interesting, less than $5 \%$ was rated "Unsatisfactory" and "very unsatisfactory" for their 
experience in using this service, which mean that this application is acceptable use by the respondent.

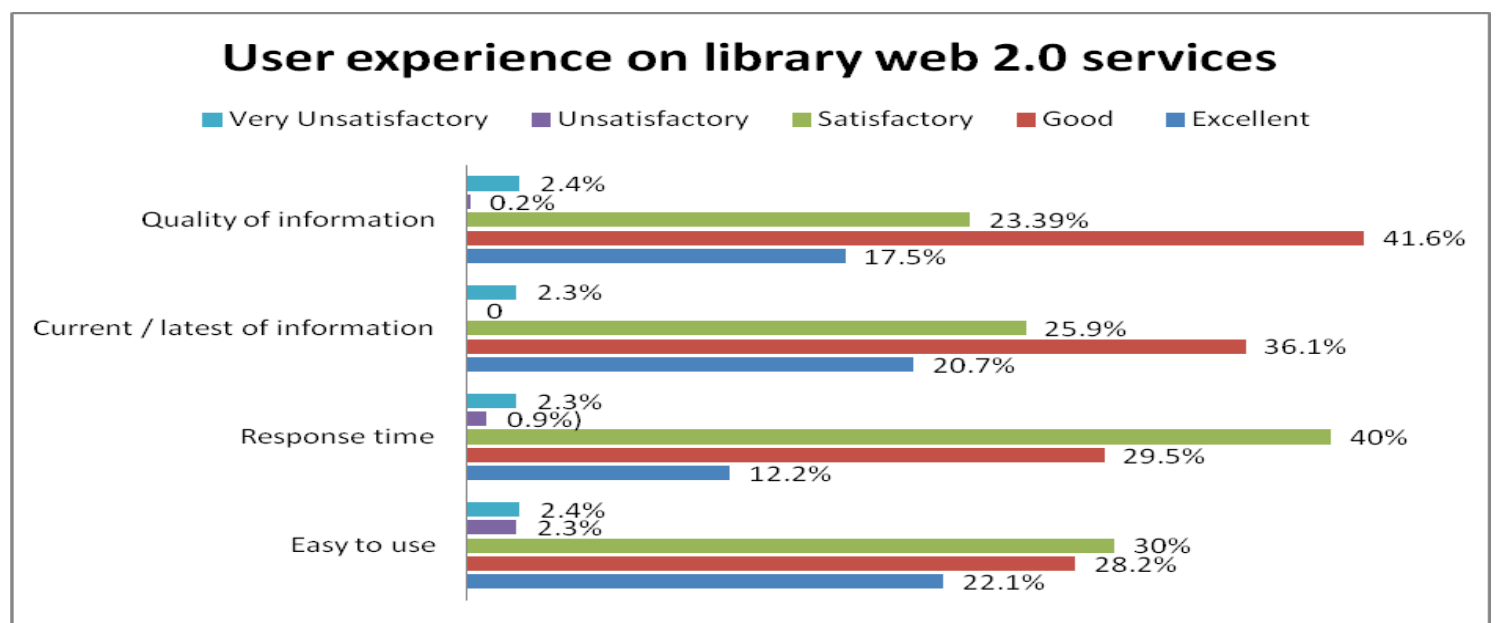

Figure 6: Respondent Activities on Library Web 2.0 Services

\section{Web 2.0 services perception}

Table 2 shows that there are different perceptions towards the use of Web 2.0 services among respondents. Based on the findings, the number of respondents who rated "Strongly Agreed" $(24.8 \%)$ in using Web 2.0 applications was higher than other modes like emails or phone calls.

Table 2: Respondents Perception about Use of Web 2.0 Application

\begin{tabular}{|l|l|l|l|l|l|l|}
\hline \multicolumn{1}{|c|}{} & $\begin{array}{l}\text { Strongly } \\
\text { Not } \\
\text { Agree }\end{array}$ & Disagree & Nuetral & Agree & $\begin{array}{l}\text { Strongly } \\
\text { Agree }\end{array}$ \\
\hline \multirow{8}{*}{} & $\begin{array}{l}\text { I would prefer to use Web } \\
\text { 2.0(eg:Facebook)compared } \\
\text { to other modes (emails, } \\
\text { phone calls) as a } \\
\text { communication medium } \\
\text { among my family, teacher, } \\
\text { friends and library }\end{array}$ & $\begin{array}{l}42 \\
(6.4 \%)\end{array}$ & $\begin{array}{l}55 \\
(8.4 \%)\end{array}$ & $\begin{array}{l}133 \\
(20.2 \%)\end{array}$ & $\begin{array}{l}115 \\
(17.5 \%)\end{array}$ & $\begin{array}{l}163 \\
(24.8 \%)\end{array}$ \\
\cline { 2 - 7 } & $\begin{array}{l}\text { Web 2.0 application are } \\
\text { good medium for student to } \\
\text { do discussion among their } \\
\text { family, teachers, friends } \\
\text { and library }\end{array}$ & $\begin{array}{l}(5.9 \%) \\
\text { User }\end{array}$ & $\begin{array}{l}58 \\
(8.8 \%)\end{array}$ & $\begin{array}{l}135 \\
(20.5 \%)\end{array}$ & $\begin{array}{l}146 \\
(22.2 \%)\end{array}$ & $\begin{array}{l}133 \\
(20.2 \%)\end{array}$ \\
\cline { 2 - 4 } & $\begin{array}{l}\text { Web 2.0 application is a } \\
\text { fast medium for student to } \\
\text { do information seeking }\end{array}$ & $\begin{array}{l}51 \\
(7.8 \%)\end{array}$ & $\begin{array}{l}49 \\
(7.5 \%)\end{array}$ & $\begin{array}{l}150 \\
(22.8 \%)\end{array}$ & $\begin{array}{l}117 \\
(17.8 \%)\end{array}$ & $141(21.5 \%)$ \\
\cline { 2 - 7 } & $\begin{array}{l}\text { Library helps student in } \\
\text { seeking information } \\
\text { through library Web .0 }\end{array}$ & $\begin{array}{l}54 \\
(8.2 \%)\end{array}$ & $\begin{array}{l}74 \\
(11.3 \%)\end{array}$ & $\begin{array}{l}153 \\
(23.3 \%)\end{array}$ & $\begin{array}{l}122 \\
(18.6 \%)\end{array}$ & $99(15.1 \%)$ \\
\cline { 2 - 7 } & $\begin{array}{l}\text { Web 2.0 is a good medium } \\
\text { for student to share } \\
\text { knowledge }\end{array}$ & $\begin{array}{l}29 \\
(4.4 \%)\end{array}$ & $\begin{array}{l}62 \\
(9.4 \%)\end{array}$ & $\begin{array}{l}140 \\
(21.3 \%)\end{array}$ & $\begin{array}{l}144 \\
(21.9 \%)\end{array}$ & $\begin{array}{l}130 \\
(19.8 \%)\end{array}$ \\
\cline { 2 - 7 } & $\begin{array}{l}\text { Library are also post } \\
\text { current news about state } \\
\text { government program, } \\
\text { activities and events }\end{array}$ & $\begin{array}{l}44 \\
(6.7 \%)\end{array}$ & $72(11 \%)$ & $\begin{array}{l}148 \\
(22.5 \%)\end{array}$ & $\begin{array}{l}137 \\
(20.9 \%)\end{array}$ & $105(16 \%)$ \\
\hline
\end{tabular}




\begin{tabular}{|l|l|l|l|l|l|l|} 
& $\begin{array}{l}\text { In summary, I am } \\
\text { benefitting a lot } \\
\text { academically through Web } \\
2.0 \text { application }\end{array}$ & $\begin{array}{l}(7.2 \%) \\
\text { 2. }\end{array}$ & $\begin{array}{l}64 \\
(9.7 \%)\end{array}$ & $\begin{array}{l}149 \\
(22.7 \%)\end{array}$ & $\begin{array}{l}129 \\
(19.6 \%)\end{array}$ & $\begin{array}{l}115 \\
(17.5 \%)\end{array}$ \\
\hline
\end{tabular}

Interestingly, it can be seen that most of the respondents agreed and strongly agreed that Web 2.0 applications are a good medium for students to facilitate discussion among their family, teachers, friends, and library (22.2\% "Agree" and $20.2 \%$ "Strongly agree"). They believed that it is a fast medium to seek information (17.8\% "Agree" and $21.5 \%$ "Strongly agree"). Web 2.0 is a good medium for students to share knowledge (21.9\% "Agree" and $19.8 \%$ "Strongly agree"). However the "Neutral" perception also scored higher in 3 categories which respondents indicated that Web 2.0 application is a fast medium for student to do information seeking $(22.8 \%)$, Library helps students in seeking information through library Web 2.0 services $(23.3 \%)$, Web 2.0 is a good medium for students to share knowledge $(21.3 \%)$, Library posts current news about state government programs, activities and events $(22.5 \%)$, and respondents benefitting a lot academically through Web 2.0 applications. Only less than $10 \%$ of respondent indicate that they strongly disagree for all the categories below, of which the lowest is $4.4 \%$ of respondents indicated that they strongly disagree that Web 2.0 can be a good medium for students to share their knowledge.

In the last question the respondents were asked to indicate whether the library should provide or not one of the following types of Web 2.0 applications in order to help their users in research and learning. Based on the results, it is indicated that the highest response for each application are "Strongly agree" and "Agree". Most of the respondents vote "Strongly agree" for Facebook (39\%) and YouTube (37\%), which means the users hope that the library should provide these two applications in the process to help them in their research and learning. Next higher vote is for Blog (26.8\% "Strongly agree"), Instant Messaging (26.3\% "Strongly agree"), Wikis (26.2\% "Strongly agree"), Photosharing (Flicker) $(23.6 \%$ "Strongly agree"), and RSS (20.2\% "Strongly agree"). Only less than $10 \%$ of respondent indicate that they do not strongly agree for all the categories below which, the lowest is $3.3 \%$ of respondents indicate that they strongly disagree that library should provide Youtube access.

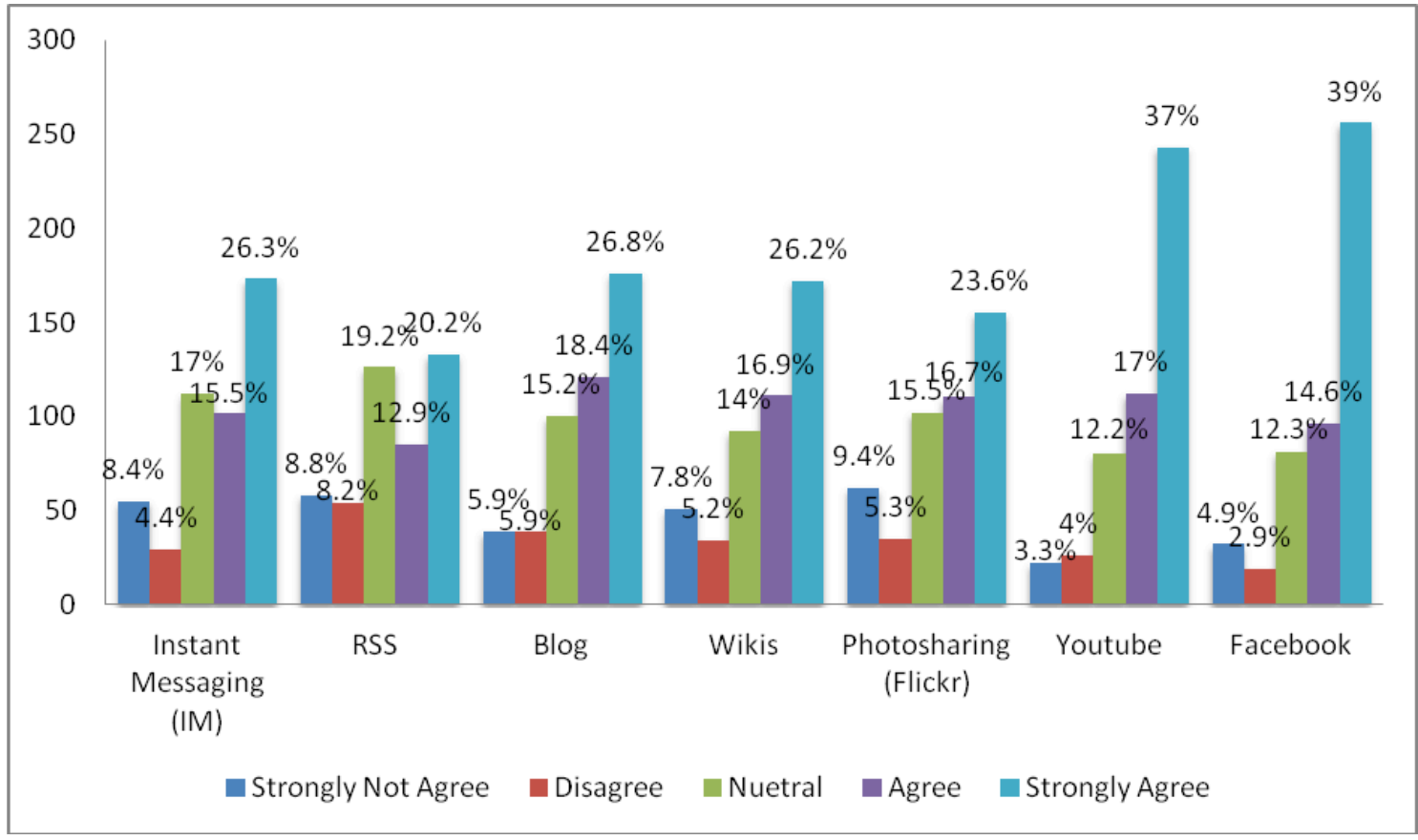

Figure 7: Respondent Opinion on Library Web 2.0 Services 


\section{Discussion and Conclusion}

Indeed, it is undeniably true that educational institutions currently have been familiarized with the application of technology in its implementation of teaching and learning process holistically. In fact, the application of Web 2.0 services has tremendously contributed to assisting the students to strengthen their abilities in mastering the cognitive skills, personal skills, and inter-personal skills which are indeed vital in their effective learning process. Indeed, in order to enrich the students' competencies, school libraries play crucial roles in materializing such magnificent achievement; as it is of the utmost importance for the librarians to keep pace with their users professionally.

\section{References}

Abram, S. (2005), Web 2.0, Library 2.0 and Librarian 2.0: Preparing for the World", ImakeNews Inc., 2(1), 1-3.

A.R., Riza Aayu and A., Abrizah. (2011). Do You Facebook? Usage and Services of Facebook Page among Academic Libraries in Malaysia. The International Information \& Library Review, 43(4), 239-249.

Aziz, R. A., Arif, Z., Ramly, R. Abdullah, C. Z., \& Husaini, H. (2011). The Implications of Libray 2.0 tools in Malaysian Academic Libraries towards Reference. Proceedings of the Asia-Pacific Conference on Library \& Information Education \& Practice, 22-24 June 2011, Putrajaya, Malaysia. Asia Pacific Conference Library \& Information Education \& Practice, pp.579-588.

Jenkins, H. (2006), Confronting the Challenges of Participatory Culture: Media Education for the $21^{\text {st }}$ century. The McArthur Foundation, Chicago, IL.

Mohd Ismail, A and Kiran, K (2012). Reaching out to the Web User: Practices by Malaysian public libraries. ICOLIS 2012, Kuala Lumpur. LISU, FCSIT, 2012: pp. 251-252.

Nikolov, R. (1997), Distance Education via Internet- Education without Borders, invited paper, Proceedings of the Twenty Sixth Spring Conference of Bulgarian Mathematicians, Plovdiv, 22-25 April, pp. 53-66.

O'Reilly, T. (2005). What is Web 2.0: Design Patterns and Business Models for the Next Generation of Software, O'Reily Net.

Aziz, R. A., Arif, Z., Ramly, R. Abdullah, C. Z., \& Husaini, H. (2011). The Implications of Libray 2.0 tools in Malaysian Academic Libraries towards Reference. Proceedings of the Asia-Pacific Conference on Library \& Information Education \& Practice, 22-24 June 2011, Putrajaya, Malaysia. Asia Pacific Conference Library \& Information Education \& Practice, pp.579-588.

Socialbakers.com. (2013). Malaysia Facebook Statistics. Retrieved from http://www.socialbakers.com/facebook-statistics/malaysia

Valkenberg, P. M., and Peter, J. (2009). Social consequences of the internet for adolescents. Current Direcions in Psychological Science 18(1), 1-5. 